\title{
Conceito e espaço da pequena empresa na estrutura industrial: heterogeneidade e formas de inserção
}

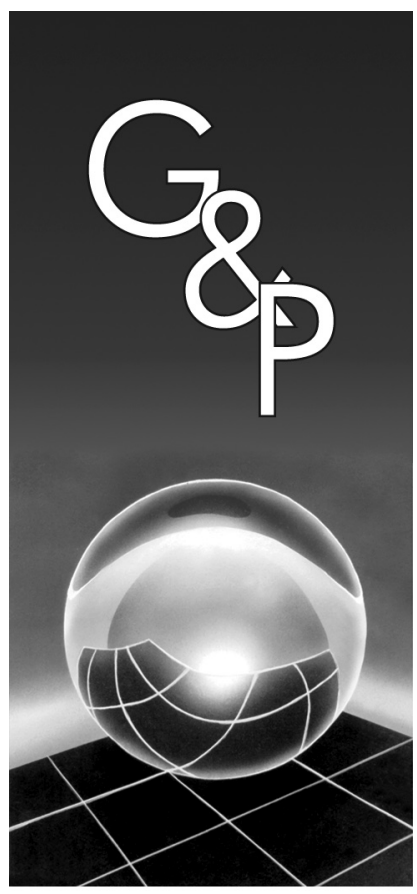

Maria Carolina de Azevedo Ferreira de Souza

Leonel Mazzali

\begin{abstract}
Resumo
Com base no exame da literatura pertinente, este trabalho busca ampliar o debate sobre o conceito de pequena empresa e identifica as formas de sua inserção na estrutura industrial. Ficou evidenciada a conceituação da pequena empresa como "pequeno capital", cuja posição e desempenho estão estreitamente vinculados ao processo de oligopolização. Nessa direção, procurou-se deixar clara a existência de quatro possíveis trajetórias de inserção para o segmento: disputa de espaço em mercados ainda pouco oligopolizados e com acentuada concorrência em preços; exploração de novos "nichos" de mercado; organização "em rede", com predominância de pequenas empresas e sem liderança explícita de grandes empresas; $e$ inserção em redes de subcontratação comandadas por grandes empresas. Frente a esse conjunto de trajetórias, fica evidente que é inadequado o tratamento das pequenas empresas como um bloco homogêneo (ou como uma "questão geral"), seja no que se refere às condições que explicam sua sobrevivência e seu crescimento, seja no âmbito das medidas de política econômica voltadas à sua promoção. $O$ importante passa a ser não o porte, mas antes o potencial de contribuição para a obtenção dos resultados planejados ao se definir medidas de apoio, entre elas a preservação e aumento do emprego.
\end{abstract}

Palavras-chave: Pequena empresa. Estrutura industrial. Trajetórias de inserção.

\section{Introdução}

As cifras relativas à participação das pequenas empresas no número total de empresas e no emprego, significativas na maior parte dos países e mesmo (e especialmente) em momentos de crise, as referendam como um instigante objeto de análise. O interesse parte, em geral, da constatação da existência e permanência continuada desse porte de empresa, apesar de suas desvantagens estruturais, particularmente no acesso ao financiamento e aos benefícios das novas tecnologias, e se desdobra em duas principais vertentes. De um lado, estudos para entender/ mensurar o peso em termos da sua contribuição para o emprego e para o desenvolvimento. De outro, em função do peso em termos do número de unidades, no emprego, e possibilidades de contribuição para o desenvolvimento, integra o rol dos alvos de políticas públicas, o que se justifica pelas fragilidades inerentes ao pequeno porte.

Mas, o que define e delimita o objeto, isto é, o que se trata quando o tema é pequena empresa? As classificações variam de país para país e de acordo com os objetivos, em especial, das políticas de apoio e promoção. Apesar da variedade de cortes, classificações são úteis, mas os critérios têm sempre certo grau de arbitrariedade, em grande medida, ligadas aos seus propósitos; de qualquer forma, são classificações e não uma definição. Permanece ainda, por parte de alguns autores e de algumas instituições, como apontado por Gibb (2000), uma leitura algo romântica e desprovida de fundamentação teórica sobre o conceito e a inserção das pequenas empresas na estrutura industrial. Visando contribuir para o aprofundamento e sistematização do conhecimento sobre as especificidades das pequenas empresas e as características de sua presença, ou funcionalidade, em diferentes estruturas produtivas, este trabalho tem dois objetivos: apresentar elementos que permitam ampliar o debate sobre o conceito de pequena empresa (ou pequeno negócio) e identificar os possíveis espaços na estrutura industrial, avaliando os condicionantes de sua sobrevivência.

Busca-se oferecer um conjunto de parâmetros para a discussão teórica e para a formulação de políticas voltadas às pequenas empresas, a partir de um estudo 
exploratório, o qual, segundo Selltiz et al. (1974, p. 60), além de ter "como objetivo a formulação de um problema para investigação mais exata ou para a criação de hipóteses", pode ter:

outras funções: aumentar o conhecimento do pesquisador acerca do fenômeno ...; o esclarecimento de conceitos; o estabelecimento de prioridades para futuras pesquisas; ... (SELLTIZ et al., 1974, p. 60).

A proposta do trabalho é reunir, a partir de pesquisa bibliográfica e de resultados de entrevistas em uma amostra de pequenas empresas, um conjunto de elementos que permitam mostrar que o segmento dessas empresas é, em seu interior, heterogêneo - pelo número de empregados, pelos produtos e processos, pelas formas de sua inserção em diferentes mercados. Em decorrência disso, propõe-se que não é adequado analisar as pequenas empresas como um bloco homogêneo (ou como uma "questão geral"), seja no que se refere às condições que explicam a sua sobrevivência e seu crescimento (e desaparecimento), seja, principalmente, no que tange à definição e proposição de política econômica voltada à sua promoção. Reside nesse aspecto a principal contribuição que se espera deste trabalho, pois o que se observa é que, embora haja um considerável número de ações de apoio a esse segmento, no geral, não são definidas levando em consideração os diversos "subsegmentos", com o que parte (ou o total) dos efeitos esperados de tais medidas pode não se concretizar. A explicação está tanto no fato de que boa parte das empresas, pelas características de sua inserção, não será alcançada por tais ações, quanto porque parte significativa dos benefícios pode não ser apropriada pelas empresas objeto das ações. Isso pode ocorrer, por exemplo, no caso de pequenas empresas participantes de redes de subcontratação comandadas por grandes empresas clientes, que, via maior poder de negociação, podem se apropriar de parte dos benefícios pela redução de preços exigida de seus fornecedores.

Esses aspectos nem sempre são ressaltados em trabalhos sobre o tema pequenas empresas e não são usuais nem mesmo em levantamentos sobre o número e localização regional das pequenas empresas. Em parte porque, enquanto há diversas fontes de informação que facilitam levantamentos sobre "quantas são e onde estão as pequenas empresas", não há a mesma facilidade de fontes para estudos que foquem "como estão inseridas as pequenas empresas". Trabalhos dessa natureza requerem pesquisas que vão além de fontes secundárias, embora possam se beneficiar delas se focarem além da localização, a participação das pequenas empresas nos diferentes setores, o que permitiria uma aproximação com as diferentes formas de inserção.
A análise neste trabalho tem como pressuposto que, apesar das dificuldades, a pequena empresa, considerada como particular segmento no conjunto das unidades produtivas, tem presença continuada, mas em espaços delimitados, com variadas formas e intensidade da contribuição. A proposta é apresentar e refletir sobre alguns dos possíveis espaços para as pequenas empresas na estrutura produtiva, como um passo necessário para futuros estudos que além de número e localização abranjam as formas de inserção e os diversos "como" elas se inserem, com maiores ou menores possibilidades de sobrevivência e expansão.

O esforço se voltou, em primeiro lugar, para o exame da literatura pertinente, evidenciando a visão dos principais autores que discutem o conceito e o papel da pequena empresa. De acordo com Selltiz et al.:

Num estudo exploratório, o foco da resenha se volta para hipóteses que podem servir para orientar futuras pesquisas. As hipóteses podem ter sido explicitamente apresentadas por pesquisadores anteriores; neste caso, a tarefa consiste em reunir as várias hipóteses apresentadas, avaliar sua utilidade com base para pesquisa mais ampla e verificar se sugerem novas hipóteses. (SELLTIZ et al., 1974, p. 62-63)

Tendo em vista os objetivos deste texto, os principais autores de referência selecionados são: Curran (2006); Curran e Burrows (1993); Dei Ottati (2003); Delatre (1982); Sengenberger (1988); Sforzi (2003); Souza (1995); Steindl (1945, 1952); e Torrès e Julien (2005).

Em segundo lugar, os pontos destacados a partir da revisão bibliográfica, procedimento metodológico básico, dada a natureza deste trabalho, foram reforçados levando-se em conta os resultados de pesquisas junto a pequenas empresas que vêm sendo efetuadas de maneira continuada há mais de 20 anos por um grupo de pesquisadores do qual os autores fazem parte. Interessa destacar os resultados de uma das pesquisas mais recentes, realizada desde 2002, junto ao setor de transformados plásticos, no âmbito de um projeto mais amplo e de longo prazo do grupo de pesquisa. Esse setor é útil aos objetivos aqui propostos, pois tem predominância de pequenas empresas, com diversas formas de inserção, de fornecedoras de grandes montadoras a pequenas empresas "independentes", com produtos voltados para o mercado final comercializados no varejo e a pequenas empresas inseridas em concentrações geográficas de empresas de um determinado setor, posto que muitas das empresas pesquisadas estão localizadas no Grande ABC Paulista.

O trabalho está estruturado em seis seções. A primeira é introdutória. Na segunda, é apresentado e discutido o referencial teórico/analítico para o estudo da pequena empresa e de sua inserção na estrutura industrial. A terceira é dedicada a uma reflexão sobre as usualmente citadas vantagens competitivas das pequenas empresas, que não podem ser 
tratadas como dadas, sem maiores qualificações. A quarta apresenta uma proposta de tipologia para, em seguida, analisar as trajetórias possíveis para as pequenas empresas. Na quinta, são apresentadas algumas evidências empíricas, com base nos resultados de pesquisa de campo junto ao setor de transformados plásticos. Finalmente, na sexta seção, algumas conclusões são indicadas e apresentadas possibilidades para futuras pesquisas.

\section{Sobre o conceito de pequena empresa e sua inserção na estrutura industrial}

Torrès e Julien (2005) identificam na literatura anglosaxônica uma espécie de "paradigma orientador da pesquisa em pequenas empresas", denominado por eles como "a tese da especificidade gerencial". Nesse paradigma, o pequeno negócio é considerado uma entidade específica, com problemas administrativos substancialmente distintos dos da grande empresa, com destaque para: estrutura administrativa centralizada; estratégias intuitivas e de curto prazo; baixa especialização; simplicidade e informalidade do sistema de informação e atuação em mercados locais. Curran (2006) explica que essa concepção emergiu nos EUA e na Grã-Bretanha na década de 60 do século XX, tornando-se fundamental para acentuar a contraposição entre pequena e grande empresa e para identificar o papel das pequenas empresas no sistema econômico.

De acordo com essa conceituação:

Isoladamente o tamanho não é uma variável suficiente para definir se uma empresa necessariamente forma parte de uma população de pequenos negócios. (TORRÈS; JULIEN, 2005, p. 359).

Daí a importância atribuída por vários pesquisadores - Curran e Blackburn (2001), D'Amboise e Muldowney (1988), Johansson (2004) e Cope (2005) - às denominadas variáveis qualitativas.

A grande variedade de formas/tipos de empresas, operando nos mais diversos setores da economia - de fabricação de velas a software para computadores - e dos diferentes contextos de origem - étnico, cultural e educacional -, levam Torrès e Julien (2005) a questionar a "tese da especificidade gerencial", tendo como base a seguinte observação:

A idéia, por exemplo, de que o proprietário de uma pequena doceria com 2 empregados, o proprietário-gerente de uma empresa de eletrônica high tech, com 10 empregados (metade dos quais possui $\mathrm{PhD}$ ), e um fazendeiro com 300 acres, 2 empregados, mais trabalhadores temporários, compartilham as mesmas visões de mundo, os mesmos problemas organizacio- nais e trabalhistas é claramente questionável. (CURRAN; BURROWS, 1993, p. 180).

Torrès e Julian (2005, p. 357) afirmam que:

a tese da especificidade gerencial, ao pretender uma homogeneidade das empresas que integram o segmento das pequenas empresas, é contraditória com a profunda heterogeneidade que marca o segmento. (TORRÈS; JULIAN, 2005, p. 357).

De fato, a observação de Torrès e Julien (2005) evidencia a complexidade do objeto de análise - pequena empresa ou pequeno negócio -; de um lado, a busca de uma característica central que defina a sua natureza, em contraposição à grande empresa; de outro, a necessidade da identificação de uma tipologia, que abranja as diferenças associadas às formas de inserção na estrutura industrial.

A característica central que define e delimita o pequeno negócio pode ser encontrada, nas restrições/barreiras que o segmento enfrenta, vis-à-vis o segmento das grandes empresas. Exemplificando:

... uma fonte de 'especificidade' provém da impossibilidade de acesso aos vários tipos de economias de escala e outra, também constatada a partir da observação empírica provém das influências culturais que restringem e conformam a ação da administração do pequeno negócio. (CURRAN, 2006, p. 206).

Esse tipo de argumento pode ser fortalecido, conforme ressaltado por Souza (1995), à luz das contribuições teóricas de Steindl $(1945,1952)$ sobre a inserção das pequenas empresas na estrutura industrial, no bojo de sua crítica à abordagem marshalliana do processo de crescimento das empresas. Steindl destaca a descontinuidade, as assimetrias e o diferencial de vantagens como as principais características no que se refere à estrutura por tamanho de empresas. A passagem de pequena para grande empresa requer a superação de consideráveis barreiras, na medida em que as vantagens inerentes à primeira - as vinculadas às economias de escala e as referentes às condições de acesso às fontes de financiamento - não são elimináveis e não são acessíveis (ao menos em iguais condições) a pequenas empresas.

Para o autor, no rol dos fatores que influenciam a posição das grandes e pequenas empresas, as economias de escala ocupam o lugar central. Mesmo considerando a possibilidade de que futuros desenvolvimentos tecnológicos pudessem comprometer certas economias derivadas do aumento do tamanho das plantas produtivas, adverte que as vantagens da pesquisa industrial (praticamente acessível apenas às grandes empresas, dado o alto custo) continuariam a dar superioridade às maiores empresas.

As grandes empresas podem já nascer grandes e as pequenas podem morrer antes de crescer. Essa é uma 
afirmação vigorosa de Steindl contrapondo-se à visão microeconômica convencional. Apesar disso, o autor (STEINDL, 1945) aponta algumas explicações para a existência continuada das pequenas empresas (como segmento e não de forma individual). Dentre elas, o fato de que o grande capital empresarial não brota do chão (sua oferta não é elástica); depende do crescimento do capital já existente. Assim, embora as pequenas empresas percam terreno continuamente, o processo é lento.

A argumentação de Steindl sobre a convivência de empresas de diferentes tamanhos no mercado não deixa dúvidas sobre as condições adversas às pequenas empresas, ressaltando que as assimetrias favorecem as grandes empresas (o grande capital). Isso, todavia, não pode ser entendido como uma inevitável tendência ao desaparecimento das pequenas empresas como pequeno capital. As conseqüências levam mais a pensar-se em uma intensa rotatividade de pequenas empresas, de forma a configurar uma organização industrial caracterizada pelo corte estrutural - pequenas, médias e grandes empresas - com marcado diferencial de vantagens e, por decorrência, de margens e taxas de lucro, segundo o porte de empresas.

No que se refere à existência continuada das pequenas empresas, Steindl destaca ainda que, em certos casos, ela pode ser explicada pelas próprias condições oligopolísticas da indústria.

A razão é que as grandes empresas tendo conseguido firmar-se como líderes de preço teriam pouco a ganhar com a eliminação de pequenas empresas que respondem apenas por uma pequena parcela da oferta total da indústria. (STEINDL, 1945).

A existência de certo número de pequenas empresas poderia ainda ser útil em outros sentidos. Por exemplo, servindo de prova inconteste no caso de a indústria necessitar defender-se de acusações de monopólio. A argumentação do autor ressalta, pois, que, embora não haja sinais apontando para sua completa eliminação, a dinâmica, as funções, o desempenho, a sobrevivência e a acumulação de capital das pequenas empresas vinculam-se, em grande medida, ao processo de oligopolização, ao potencial de acumulação e às estratégias das grandes empresas nas diversas estruturas de mercado.

Posteriormente, ao escrever, em 1972, a introdução para uma edição em espanhol de Small and Big Business, o autor, de certa forma, reafirma seu ceticismo ao reconhecer que:

... tal como me equivoquei ao descuidar das deseconomias, expressei-me em termos por demais adversos sobre as possibilidades das pequenas empresas, embora meus comentários sobre o grau decrescente de sua independência tenham sido confirmados pelos desenvolvimentos posteriores. (STEINDL, 1972, p. 17).
Essa reconsideração sobre o espaço das pequenas empresas levou em conta que, ao longo dos 25 anos entre a publicação original e a segunda edição do livro, desenvolveram-se algumas atividades propícias a uma significativa participação de empresas pequenas (especialmente alguns tipos de serviços e fabricação de produtos especializados e personalizados). Nesse período, também foi ampliada a tendência à subcontratação por parte das grandes empresas, movimento que vem se mantendo e se fortalecendo, de tal forma que a subcontratação é atualmente um componente importante das estratégias das empresas. O movimento de desintegração vertical abre espaços para que alguns tipos de pequenas empresas possam atuar em cooperação com grandes empresas contratantes, preservando relativa autonomia. Entretanto, esses "subcontratados" - produtores ou distribuidores -, por serem parceiros pequenos e em grande número, em situação de barganha com poucas e grandes empresas, ocupam uma posição economicamente frágil e sua independência é, em grande medida, fictícia.

A pertinência (e atualidade) do realce a esse particular tipo de pequena empresa, no que tange à sua maior capacidade de enfrentar as adversidades próprias ao pequeno capital, é notável. O autor deixa claro que o processo de concentração havia alcançado uma nova (e em patamar mais elevado) etapa. Alguns fatores tenderam a favorecer ainda mais as grandes empresas: a automação, a crescente importância das atividades de pesquisa e desenvolvimento e o avanço dos computadores.

A permanência das pequenas empresas deve-se, também, a alguns fatores, não muito honrosos, do sistema econômico. A atitude de "jogador" de pequenos empresários é uma delas. A atração pelo possível status de empresário e pelas vantagens de "ser seu próprio patrão" e a determinação (ou necessidade) de buscar um empreendimento próprio como alternativa ao desemprego (especialmente em uma situação de desemprego generalizado) fazem com que empresários com pouco capital (mais ambiciosos e com espírito aventureiro) aceitem riscos relativamente altos com baixa (mas aceitável, nas circunstâncias) remuneração. A persistência de altos índices de desemprego aumenta o número de candidatos a pequenos empresários e pode comprimir ainda mais a remuneração em termos reais, principalmente dos empresários mais próximos à situação de "empregados por conta própria”. O movimento resultante é o de uma corrente contínua de entradas e saídas de pequenas empresas.

Assim como o desemprego, "imperfeições de mercado" derivadas de motivos irracionais também podem ser citadas como um desses fatores pouco nobres que favorecem a preservação do grupo das pequenas empresas. Por exemplo, a diferenciação (em contraste com a produção em grande escala de produtos padroni- 
zados das grandes empresas) muitas vezes significa altos custos sem oferecer qualquer vantagem objetiva. Apesar disso, pode representar significativa oportunidade para pequenas empresas voltadas a oferecer produtos que atendam às necessidades de consumidores desejosos de "independência" com relação a produtos massificados. $\mathrm{O}$ culto a determinadas marcas fornece um exemplo bastante atual desse tipo de diferenciação.

Ainda no campo das imperfeições, para as pequenas empresas, imperfeições no mercado de trabalho podem ser ainda mais importantes que as dos mercados dos produtos. Muitas pequenas empresas só conseguem sobreviver porque estão em indústrias nas quais não há grandes pressões para a adoção de técnicas poupadoras de emprego, e a mão-de-obra é de baixo custo e não organizada. Essa situação permite que pressões típicas da concorrência em preço sejam contrabalançadas por reduções no custo da mão-de-obra.

Os fatores mencionados e os argumentos de Steindl podem ser utilizados não só para explicar a tenaz sobrevivência das pequenas empresas, mas também (e principalmente) para pôr em relevo sua fragilidade no que tange à independência econômica e política, diante do avanço do processo de concentração de capital, o que justifica políticas diferenciadas voltadas para esse segmento. Por outro lado, é de se esperar que, a despeito das evidentes fragilidades, as pequenas empresas apresentem certas características, ou, mais especificamente, vantagens, possibilitando que alcancem determinada posição competitiva. Entre outras, estrutura organizacional mais simples e maior flexibilidade (relativamente à complexidade das grandes empresas) são usualmente citadas. Entretanto, essas possíveis vantagens não podem ser aceitas como dadas, sem maiores qualificações, como se explicita no próximo item.

\section{Qualificações sobre as possíveis van- tagens competitivas das pequenas empresas}

Tendo por referência a denominada "visão da empresa sob a perspectiva dos recursos", Yu (2001) identifica os tipos e a natureza dos ativos e das competências que influenciam, de modo decisivo, a flexibilidade organizacional, apontada como a base da vantagem competitiva da pequena empresa. A flexibilidade entendida como a capacidade de responder rapidamente às mudanças - internas e externas - está associada à "inércia organizacional", que é conseqüência dos investimentos em ativos físicos especializados, da rigidez das rotinas/processos e da burocratização das estruturas administrativas.

A grande empresa, ao longo de sua história, efetivou elevados investimentos em capital físico e humano. Tais investimentos são altamente específicos e irreversíveis, dificultando, ou mesmo impedindo, a adoção de novos métodos. As pequenas empresas, por possuírem uma estrutura de capital - físico e humano - menos especializada e específica, são capazes de minimizar a influência da inércia, tendo uma grande capacidade de reestruturar rotinas e processos produtivos. Ademais, a proximidade das relações patrão-empregado, além de reduzir os custos de coordenação, facilita a comunicação e, por essa via, a aprendizagem e o compartilhamento do conhecimento e de valores.

O autor conclui afirmando que os dois ativos intangíveis distintivos possuídos pelas pequenas empresas são a simplicidade da estrutura organizacional e as relações entre o proprietário-empreendedor e seus funcionários. No entanto, vale ressaltar que a maior flexibilidade das pequenas empresas pode, ao final, significar menor produtividade e implica, no mínimo, dois pressupostos que podem lhes conferir conotação negativa em relação ao fenômeno da pobreza dos assalariados.

Primeiro, por possuírem tecnologia "mais atrasada", podem utilizar mão-de-obra menos qualificada (cujo aprendizado se dá, em boa parte das vezes, na própria empresa). Essa mão-de-obra se sujeita a salários menores e a contratos e condições de trabalho menos favoráveis, que chegam a não obedecer plenamente às exigências sindicais e legais. Segundo, as pequenas empresas têm vantagens quanto ao custo de mão-de-obra, beneficiando-se de certos incentivos governamentais (e outros não-oficiais) quanto aos encargos sociais, normas de admissão e demissão de funcionários, relações com sindicatos, etc. Esse tipo de "vantagem", apesar de ser um dos argumentos mais tradicionais para explicar o desempenho das pequenas empresas, ganha realce em momentos de crescente desemprego, quando se verifica maior condescendência, por parte das instituições governamentais e da sociedade, com as práticas precárias de emprego.

Também não se pode inferir que o simples fato de as relações serem informais e o convívio entre empregados, e entre estes e o patrão, ser aparentemente mais próximo conduz a relações de menor conflito e ao maior comprometimento dos empregados. É bastante questionável que a satisfação derivada de relações "mais humanas" e menos rígidas possa superar os efeitos negativos de baixos salários, condições de trabalho inadequadas e menores benefícios sociais.

Em períodos de expansão econômica, são amplos os espaços para surgimento e multiplicação das pequenas empresas. Em períodos de crise, na categoria das pequenas empresas, o ajuste de emprego é, muitas vezes, feito, não pela redução do número de empregados, mas antes pelo desaparecimento de empresas (DELATRE, 1982). Além disso, com a crise, algumas empresas médias reduzem o número de empregados, com o que "caem" para a categoria de empresas pequenas. Algumas dessas, por sua vez, 
passam a fazer parte do grupo das microempresas. Estas, aliás, tendem a proliferar em momentos de depressão econômica, nesse caso, não como sinal de vigor de uma tendência ao empreendedorismo, mas antes como uma nada elogiável consequiência de retração das atividades econômicas. A tendência ao aumento da formação de novas empresas, que então se verifica, reflete, em boa medida, os movimentos de pessoas desempregadas que não vêem outra forma de voltar a integrar-se na estrutura produtiva, aproximando-se mais de "trabalhadores por conta própria" do que de capitalistas no sentido usual do termo.

$\mathrm{O}$ aumento do número de empregos nas pequenas empresas, em paralelo à redução de empregos nas grandes empresas, não pode ser propriamente atribuído a um possível "maior dinamismo e resistência à crise" das primeiras, sendo, frequientemente, sinal de recrudescimento dessa mesma crise. A esse respeito, deve-se notar que a rotatividade entre as empresas menores (e mais novas) é bem maior que entre as médias e grandes. Estas últimas, sim, têm maior resistência à crise em termos de sobrevivência no mercado e liderança.

Dados relativos ao número de pequenas empresas, ao surgimento de novas unidades e à manutenção e ampliação do número de empregos não podem ser interpretados isoladamente. Pode ocorrer que estejam expressando muito mais o impacto que decisões internas às grandes empresas exercem sobre elas do que seu próprio dinamismo. Isto é, ao tratar das condições de competitividade e permanência das pequenas empresas no mercado, não se pode ignorar a ocorrência de movimentos marcantes no conjunto das grandes empresas. Para grande parcela das pequenas empresas, sua sobrevivência e seu desempenho devem-se ao fato de as grandes empresas terem condições de encontrar suas próprias saídas, diante de situações desfavoráveis. Entretanto, as limitações não significam que a permanência das pequenas empresas esteja vinculada apenas às decisões das grandes; há formas de inserção em que a posição das pequenas empresas não está ligada, ao menos de maneira muito estreita, às decisões estratégicas das grandes empresas, conforme se procura mostrar no próximo item.

\section{Proposição de uma tipologia das pequenas empresas}

Da discussão ao longo do texto, alguns pontos devem ser destacados, tanto no que se refere ao conceito de pequena empresa, quanto ao reconhecimento da heterogeneidade de funções (ou formas de inserção) que caracteriza as pequenas empresas.

As considerações até aqui desenvolvidas permitem apontar que as articulações entre pequenas e grandes empresas são multiformes, complexas e de origens e graus diferentes. Podem manifestar-se de diversas maneiras e obedecer a mecanismos distintos. Levando em conta as modalidades de articulação, é possível identificar diferentes tipos de empresas no segmento de pequenas empresas.

Tendo como referência a complementaridade, as pequenas empresas podem ser dependentes ou independentes. As pequenas empresas dependentes são funcionais, complementando direta ou indiretamente as grandes empresas, executando uma ou várias das operações que compõem o processo de fabricação de um produto, ou produzindo um ou mais de seus componentes.

As pequenas empresas independentes não mantêm uma ligação direta com grandes empresas e não há uma explicação única para sua inserção no mercado. Em alguns casos trata-se de pequenas empresas que atuam em setores (ou segmentos) tradicionais e competitivos com baixas barreiras à entrada e concorrência predominantemente em preço. Em outros casos, são empresas que "concorrem" com as grandes em setores mais concentrados e que só se tornam viáveis graças à maior flexibilidade, à estrutura mais simples e de menor custo e, não raro, a menores custos da mão-de-obra. Há ainda pequenas empresas "independentes" que conseguem ser bem sucedidas em estruturas industriais nas quais há liderança das grandes empresas, ocupando espaços ("nichos") em termos de produto, processo ou mercado delimitados, e sendo flexíveis o suficiente para buscar e ocupar novos espaços à medida que os que ocupam se estreitam.

Tendo como referência essas possíveis formas de inserção, em função do maior ou menor grau de "independência" das pequenas empresas, e a contribuição de Sengenberger (1988, p. 252-258), pode-se propor um conjunto de possíveis trajetórias de inserção das pequenas empresas na estrutura produtiva:

a) pequenas empresas em mercados competitivos;

b) pequenas empresas independentes em estruturas industriais dinâmicas;

c) pequenas empresas organizadas em redes sem liderança de grandes empresas; $\mathrm{e}$

d) pequenas empresas integrantes de redes comandadas por grandes empresas.

Não se pretende que essas quatro trajetórias dêem conta de explicar todas as possibilidades de atuação das pequenas empresas, mas apenas que contribuam para uma melhor compreensão de sua dinâmica. Ressalte-se que, tendo em vista os propósitos deste texto, não houve preocupação em incluir os pequenos empreendimentos que se aproximam mais de frágeis arranjos para lidar com os efeitos do desemprego. Isto é, a análise não se estendeu para os empreendimentos de sobrevivência. Considera-se que esses empreendimentos compõem um segmento particular muito heterogêneo e com particularidades que recomendam não incluí-los, sem maiores qualificações, na categoria pequenas empresas, como aqui tratadas. 


\subsection{Pequenas empresas em mercados competitivos}

A primeira trajetória diz respeito àquelas pequenas empresas nas quais a flexibilidade e a estratégia competitiva associam-se a menores custos de mão de obra (salários e benefícios sociais). Em determinadas circunstâncias, esses menores custos chegam a desempenhar importante papel, não tanto para aumentar o emprego, mas para evitar que um grande contingente de mão-de-obra chegue ao patamar do desemprego. Nesse sentido, as pequenas empresas são vistas como um mal necessário (em especial por parte das autoridades econômicas), ou como um grande potencial em termos de emprego, que deve ser apoiado e subsidiado para que possa desenvolver-se. Teriam, portanto, funcionalidade social e econômica.

Malgrado a suposta funcionalidade desse tipo de empresa, cabe uma advertência quanto à inexistência de garantias de que medidas de apoio indiscriminadas surtam os efeitos esperados. Semelhantes medidas podem levar a um estado de acomodação por parte de proprietários que, ao invés de verem-se estimulados a aumentar os esforços em inovação, tendam a ficar apoiados no "travesseiro macio" das vantagens de curto prazo, do menor custo da mão-de-obra e dos benefícios econômicos e fiscais. Ao final, a redução de custos pode implicar menor produtividade e maiores custos sociais.

Por outro lado, os diferenciais no custo do trabalho podem encorajar as grandes empresas a usar essas pequenas empresas como "amortecedores" em relação à flutuação da demanda (por exemplo, via aumento da subcontratação). Neste caso, o aumento de empregos no âmbito das pequenas empresas ocorre simultaneamente ao menor emprego nas grandes empresas, de forma que pode não conduzir ao aumento global de emprego.

Nessa trajetória, as perspectivas de inserção positiva de pequenas empresas, em termos de contribuição à competitividade, são reduzidas, até porque, freqüentemente, só têm condições de permanecer em estruturas de mercado com menores barreiras à entrada, bem afastadas, portanto, dos setores mais oligopolizados, líderes da economia.

\subsection{Pequenas empresas independentes em estruturas industriais dinâmicas}

A segunda trajetória refere-se àquelas empresas cujo surgimento, continuidade e desempenho estão bastante associados às características de seus empresários (schumpeterianos?) que, sob determinadas condições, conseguem "perceber" e reunir os elementos necessários para explorar novos "nichos" de mercado que, recorrentemente, se formam ao longo do percurso de um paradigma tecnológico.

As perspectivas nessa trajetória estão estreitamente ligadas à capacidade dos empresários de tornar a empresa mais que a expressão de suas potencialidades pessoais, mantendo-a continuamente na linha de frente, no que se refere à busca de novos "nichos". Isso se torna tão mais essencial quanto mais estreito for o ciclo de vida dos produtos e quanto mais frágeis forem as barreiras à entrada nesse "nicho". Como não se trata de um "nicho" específico, mas sim de "nichos", há nesse campo espaço garantido para a inserção positiva de pequenas empresas. Os maiores obstáculos podem ser as dificuldades de acesso ao financiamento, que podem restringir a passagem da percepção de um "nicho" para um empreendimento viável, ou limitar fortemente a expansão da empresa para um novo patamar. Nessa situação, a proposta de compra por parte de uma empresa maior pode ser vista como irrecusável. A atuação das instituições públicas e a presença ou não de medidas seletivas de promoção e financiamento, apesar de não serem o elemento estratégico, podem representar a diferença entre permanecer ou sair (por imposição ou decisão própria) do mercado.

\subsection{Pequenas empresas organizadas em redes sem liderança de grandes empresas}

A terceira trajetória diz respeito àquelas pequenas empresas que integram aglomerações geográficas de determinados setores. Para que as pequenas empresas integrantes desses particulares arranjos organizacionais de empresas construam vantagens competitivas (relativamente a empresas de fora do arranjo), é necessário que sejam capazes de desenvolver ações conjuntas e coordenadas que permitam obter ganhos e vantagens que seriam inacessíveis a uma pequena unidade individual.

O exemplo clássico desse arranjo cooperativo é dado pelas formações conhecidas como distritos industriais:

sistemas locais com uma ativa co-presença de pessoas e de um ramo de atividade consistindo de pequenas empresas independentes especializadas nas diferentes fases de um particular processo de produção. (SFORZI, 2003, p. 158-159).

A obtenção e a manutenção da vantagem competitiva são resultados da divisão - vertical e horizontal - do trabalho e da estreita colaboração entre o conjunto de empresas que compõem o distrito. Segundo Dei Ottati (2003), podem ser identificados três tipos de empresas: as empresas finais, as empresas-fase e as firmas voltadas para as atividades subsidiárias. As empresas finais se especializam, principalmente ou exclusivamente, no desenho e no marketing dos produtos, os quais elas subcontratam de outras empresas do distrito, as denominadas empresasfase. Esse tipo de empresa é essencial para a viabilidade do distrito porque faz a ligação do sistema de produção local com o mercado e com as fontes de suprimento. As empresas-fase se especializam em uma ou poucas fases do processo de produção, diferenciando-se não somente de acordo com a escala mínima eficiente, mas também 
de acordo com as habilidades e a intensidade de capital requerido. Finalmente, as firmas especializadas em atividades subsidiárias ao ramo de produção principal do distrito dedicam-se à produção de maquinário e à oferta de serviços logísticos e outros serviços de apoio.

As características dessa forma de organização coletiva - sinergias potenciais, pouca divisão de trabalho por empresa versus significativa divisão de trabalho no interior do distrito, posições pouco rígidas, poder das empresas não muito desigual e baixa hierarquia nas relações entre empresas - garantem grande flexibilidade. A organização "comunal", além de propiciar eficiência técnica, confere certo poder coletivo de manobra, normalmente acessível apenas às grandes empresas, visto que pode ampliar o peso e a voz política das pequenas empresas, inclusive no que diz respeito a demandas ao setor público.

É evidente que todas essas vantagens podem não ter caráter permanente (como, aliás, qualquer vantagem). Aparentemente, no entanto, esses distritos garantem certa importância em termos de dinamismo, desenvolvimento industrial e situação econômico-financeira das regiões em que se situam. Dessa forma, as pequenas empresas que os integram estão mais protegidas (com relação a pequenas empresas não organizadas em rede) porque, em uma situação de declínio, poderão, ao menos, beneficiar-se de sua posição relevante em termos de desenvolvimento regional. Isso lhes assegura menor grau de incerteza quanto às possibilidades de permanência continuada, talvez com um perfil remodelado.

\subsection{Pequenas empresas integrantes de redes comandadas por grandes empresas}

A quarta trajetória traduz as condições e as possíveis formas de vinculação pequenas empresas/grandes empresas, com maior ou menor grau de dependência, maior ou menor grau de autonomia, em uma relação mais ou menos assimétrica. Essa trajetória deve ser vista no quadro da nova divisão de trabalho entre empresas e das transformações que esta imprime às relações entre elas. Incluem-se aqui pequenas empresas que interagem, de diversas formas, com as grandes empresas, fazendo parte de suas estratégias, ficando, portanto, de alguma forma, sob seu controle. Em particular, a tendência no sentido de crescente desintegração vertical "para trás" das grandes empresas tem ampliado os espaços para esse tipo de interação.

Um dos casos notórios sobre as formas que as relações pequenas/grandes empresas podem assumir é o do sistema de subcontratação no Japão, que forma uma extensa rede de relações hierarquizadas e interdependentes entre as empresas. Na cúpula, encontra-se a "empresa-mãe", algumas vezes o único ou maior cliente de um número significativo de empresas subcontratadas. No interior desse sistema, pode ser observado um "efeito cascata", a partir do qual forma-se uma imensa e complexa estrutura hierárquica de contratantes e subcontratadas, rigidamente coordenada (mas exigindo cooperação), de maneira a garantir competitividade à "empresa-mãe".

Nessa forma de inserção das pequenas empresas, dada a sua amplitude, não existe um padrão único de relação pequenas empresas/grandes empresas. Situam-se, aqui, empresas "satélites", totalmente submetidas ao comando das contratantes, e empresas que se beneficiam do privilégio de estar sob o "guarda-chuva" de uma grande empresa, com funcionalidade tão alta, que adquirem forte poder de negociação. Em caso de quebra dos vínculos, a grande empresa, no mínimo, defrontar-se-á com a desvantagem representada pelo tempo necessário para encontrar, formar e adaptar um novo fornecedor. Portanto, a base e a dimensão das relações entre as empresas estão muito mais na troca de conhecimentos e experiência que na simples relação de compra e venda (como na relação de subcontratação tradicional). Quanto mais relevante for o papel das pequenas empresas na determinação da competitividade das grandes empresas, quanto menores as assimetrias no poder de negociação. Isso se dá, em particular, quando a subcontratação, ou qualquer que seja a relação, é de especialização.

As perspectivas para as pequenas empresas nessa trajetória são bem menos sombrias do que as limitadas possibilidades da primeira trajetória, visto que dizem respeito, entre outras coisas, à função clássica da pequena empresa como elemento complementar à grande empresa.

A definição das formas de inserção das pequenas empresas na estrutura produtiva, tratadas ao longo deste item, teve como referencial analítico proposições de autores de amplo reconhecimento no tratamento de temas relacionados às pequenas empresas. Portanto, as quatro formas destacadas têm respaldo teórico. No entanto, pode-se indagar se encontram respaldo igualmente em evidências empíricas. O próximo item foi desenvolvido com o intuito de contribuir para uma resposta a essa indagação.

\section{Algumas evidências empíricas}

Os pontos destacados na seção anterior, a partir da revisão bibliográfica, procedimento metodológico básico, dada a natureza deste trabalho, podem ser reforçados levando-se em conta os resultados de pesquisas junto a pequenas empresas que vêm sendo realizadas de maneira continuada há mais de 20 anos por um grupo de pesquisadores do qual os autores fazem parte. Embora sejam realizadas no âmbito de projetos diversos, e com diferentes objetivos, nessas pesquisas sempre há a preocupação de se investigar de que forma as empresas pesquisadas se inserem e têm presença continuada no mercado.

Tendo em vista os objetivos propostos para este texto, interessa destacar os resultados de uma das pesquisas 
mais recentes. Essa pesquisa vem sendo realizada desde 2002, no âmbito de um projeto mais amplo e de longo prazo do grupo de pesquisa. O principal intuito é identificar as estratégias que pequenas empresas adotam para permanecer no mercado e as principais dificuldades que enfrentam por serem de pequeno porte. Entre as questões, abertas, constantes de um roteiro para orientar as entrevistas, sempre com um dirigente, há uma voltada às especificidades da inserção da empresa nos mercados em que concorre.

A pesquisa, por seus objetivos, não foca ramos específicos, e depende da aceitação dos dirigentes em conceder as entrevistas. Pela facilidade representada pela proximidade e pela interação com outras pesquisas, o número maior de empresas é do setor de transformados plásticos. Esse setor é útil aos objetivos aqui propostos, pois tem predominância de pequenas empresas, com diversas formas de inserção, de fornecedoras de grandes montadoras a pequenas empresas "independentes", com produtos voltados para o mercado final comercializados no varejo, e a pequenas empresas inseridas em concentrações geográficas de empresas de um determinado setor, posto que muitas das empresas pesquisadas estão localizadas no Grande ABC Paulista.

O número de empresas pesquisadas é relativamente pequeno, considerando-se o universo de pequenas empresas (com a continuidade da pesquisa será ampliado). Entretanto, os resultados podem ser considerados válidos, uma vez que as empresas às quais se referem (17 empresas) foram selecionadas levando-se em conta a forma de inserção. Pelas particularidades do setor, uma mesma empresa pode ter mais de uma forma de inserção (por exemplo, alguns itens de linha própria e outros de subcontratação), mas considerou-se a forma predominante de acordo com o entrevistado. Das 17 empresas do setor de transformados plásticos pesquisadas, 9 estão localizadas no Grande $\mathrm{ABC}, 3$ na região de Campinas, 3 na cidade de São Paulo, 1 em Osasco e 1 em Carapicuíba.

As empresas situadas no Grande $\mathrm{ABC}$ são exemplos de pequenas empresas localizadas em aglomerações setoriais (forma de inserção "c" conforme desenvolvido na seção 4), mas as vantagens apontadas pelos empresários não vão além das derivadas do acesso à mão-de-obra especializada e proximidade com parte dos clientes. Ações de cooperação ainda são incipientes e dependem da concretização de alguns projetos para se consolidarem. As vantagens das empresas locais relativamente a empresas situadas em outras localidades não são expressivas, restringindo-se praticamente às externalidades positivas próprias da localização. Pelos comentários dos entrevistados, ainda não se dedica especial atenção à construção de relações que levem a vantagens internas ao setor na localidade, de forma a alcançar força de negociação e escala.

Independentemente da localização, boa parte das empresas pesquisadas são fornecedoras de outras empresas (embalagens diversas, invólucros, peças e componentes) de diversos setores como alimentos e bebidas, cosméticos, eletroeletrônicos e automotores. Enquadram-se, portanto, na trajetória "pequenas empresas integrantes de redes comandadas por grandes empresas", tratada na seção anterior. Os entrevistados nessas empresas destacaram as dificuldades de negociação com grandes clientes. As especificações têm de ser atendidas rigorosa e tecnicamente nos prazos, são exigidas instalações apropriadas, atualização tecnológica em equipamentos, processos e materiais, e mesmo a revisão das práticas de gestão. Se por um lado essas exigências são consideradas positivas, pois a empresa mantém-se atualizada, por outro, há dificuldades para repasse dos custos dessa atualização. Caracteriza-se, portanto, uma relação assimétrica de poder, que, de acordo com os entrevistados, comprime a lucratividade, dificultando novos investimentos.

Essa assimetria no poder de negociação é atenuada no caso de empresas que já alcançaram determinado grau de desenvolvimento tecnológico, com base, de um lado, em investimento em laboratório e equipes de pesquisa (embora ainda modesto relativamente ao de grandes empresas), de outro, no desenvolvimento de produtos em conjunto com os grandes clientes. Das empresas entrevistadas, apenas uma pode ser considerada nesse estágio. A empresa, que tem mais de 30 anos no mercado, há aproximadamente 10 anos passou por uma crise, com perda de alguns dos principais dos clientes.

Visando a sobrevivência e posterior ampliação da empresa, houve uma reestruturação, com renovação da diretoria. Os novos diretores, integrantes da família, relativamente jovens e com formação universitária, decidiram admitir uma equipe de profissionais com larga experiência na produção e com conhecimentos do mercado. A retomada de alguns grandes clientes e a conquista de novos contratos exigiram que a empresa se adaptasse e investisse em laboratório próprio de pesquisa, para poder desenvolver projetos em conjunto com os clientes. A estratégia foi bem sucedida, o laboratório foi sendo consolidado e hoje está capacitado até para o desenvolvimento de novos materiais, o que lhe confere condições de disputar, com competitividade, novos contratos com algumas empresas com maior disponibilidade de capital.

Quanto à trajetória "pequenas empresas independentes em estruturas industriais dinâmicas", não foi possível (ao menos até o momento) identificar alguma empresa do setor de transformados plásticos que se enquadre perfeitamente na categoria. A esse respeito vale destacar, no caso desse setor, que as inovações estão mais nos setores a montante (máquinas, resinas, compósitos, moldes) do 
que na etapa de transformação (transformação, como indica o nome, de resinas plásticas em produtos de plásticos, por meio de processos físicos, como a extrusão, a injeção, etc.). Além disso, os segmentos que requerem maior atualização tecnológica e escala são compostos fundamentalmente por grandes empresas, algumas multinacionais. A despeito dessas particularidades, a empresa mencionada no parágrafo anterior, embora exemplifique empresa integrante de rede de subcontratação comandada por grandes empresas, de certa forma pode ser utilizada como exemplo de empresa em segmento dinâmico, pois concorre em um dos segmentos do setor que requer maior atualização tecnológica e das práticas de gestão e comercialização. O desenvolvimento interno de projetos requer pessoal com conhecimentos específicos; a atualização das práticas de gestão e de comercialização, mais que resultado de decisões internas é resposta positiva à imposição derivada da dinâmica do particular segmento em que atua. Sem atualização, estreitam-se grandemente as chances de vencer grandes empresas em "concorrências" para novos contratos com grandes empresas multinacionais.

No caso das empresas com produtos voltados para o mercado final (podem ser consideradas ilustrativas da categoria de inserção "pequenas empresas independentes"), a principal restrição, como seria de se esperar, refere-se à comercialização dos produtos. Os produtos, pelas características das empresas, não têm marcas conhecidas e, em boa parte, disputam espaços com produtos semelhantes (sacolas, sacos de lixo, potes para uso doméstico, vassouras, rodos, etc.). Consequientemente, o preço é, no geral, a principal variável na comercialização do produto. Foram ressaltadas também as dificuldades de acesso a canais de distribuição (por exemplo, entrada no grande varejo) e a desigualdade no poder de negociação (assimetrias) quando se consegue acesso a esses canais. Não se notou receio de que as empresas sejam excluídas do mercado, ao menos no curto prazo, mas as expectativas dos entrevistados são, em geral, apenas de sobrevivência, não de crescimento, associadas ao reconhecimento da falta de condições para investimentos em atualização tecnológica. Esta, aliás, sequer é considerada uma condição de maior urgência nesses segmentos específicos.

\section{Considerações finais}

Ao longo deste texto, procurou-se evidenciar a heterogeneidade do segmento das pequenas empresas, tanto no tamanho relativo das empresas, quanto nas formas de inserção. Heterogeneidade nas formas de inserção significa diferentes necessidades no que tange à continuidade das pequenas empresas no mercado e diferenças também na possível contribuição delas; algumas apenas pelo emprego em si de pessoas com baixa qualificação; outras para o emprego com mais qualificação; outras ainda com capacidade de contribuir para a competitividade do setor em que se inserem.

A partir da pesquisa bibliográfica, foi possível chegar à proposição de quatro possíveis trajetórias de inserção para o segmento: disputa de espaço em mercados ainda pouco oligopolizados e com acentuada concorrência em preços; identificação e exploração de oportunidades em "nichos" de mercado; parte integrante de aglomerações setoriais de empresas, sem liderança explícita; e inserção em redes de relações, mais frequientemente de subcontratação, comandadas por grandes empresas.

Com relação à primeira forma de inserção, apontou-se que, em setores pouco oligopolizados, embora as pequenas empresas sejam predominantes em número, têm pouca influência no desempenho dos setores em que se inserem. Sua sobrevivência está relacionada à capacidade de resistir à pressão representada pela concorrência essencialmente em preços. Essa resistência significa, na maioria das vezes, vantagens fundadas em menores custos, associadas à baixa qualificação e alta rotatividade da mão-de-obra. Rotatividade que se estende para as pequenas empresas, que participantes "marginais" no setor, com baixas barreiras à entrada (e saída) estão sujeitas a elevada mortalidade. Esta não desestimula a entrada de novas pequenas empresas, daí a rotatividade.

$\mathrm{Na}$ segunda trajetória, desempenham papel relevante a "perspicácia empresarial" e a capacidade empreendedora, tão propaladas quando se trata do pequeno empreendimento, cuja referência é a busca constante de novos "nichos", mais precisamente, a exploração de "franjas" do mercado não exploradas (em determinado período) pelas grandes empresas. Trata-se de um campo no qual surgem oportunidades tendo como base, entre outras, a sofisticação de produtos, a introdução de novos produtos, a prestação de serviços especializados, etc. Algumas oportunidades estão na produção em setores na fronteira tecnológica, que, pela etapa (do ciclo de vida) ainda em desenvolvimento, muitas vezes, são fabricados/desenvolvidos em caráter quase experimental, sem escala, e, portanto, com elevado risco, especialmente na esfera da comercialização.

Na terceira trajetória, a vantagem competitiva não está associada à ação de agente individual; depende da ação coordenada de um conjunto de agentes. Nessa forma de inserção, pequenas empresas em aglomerações setoriais sem a liderança de grandes empresas, a competitividade será definida pela eficiência da forma da organização coletiva, envolvendo o processo de divisão e de coordenação de trabalho entre pequenas empresas especializadas. Este só ocorrerá se houver a percepção, por parte dos agentes envolvidos, das vantagens (para cada unidade individual) da atuação conjunta, tendo como eixo alguns objetivos comuns. Evidenciaram-se, com base na revisão bibliográfica e nas entrevistas, as dificuldades e a complexidade imanente à mobilização, à coordenação e ao controle do 
conjunto de agentes. A mera aglomeração de pequenas empresas, de modo particular, com produtos que disputam o mesmo segmento de mercado, isto é, com baixa especialização, não é suficiente para gerar competitividade ao setor na localidade e às próprias pequenas empresas que o integram.

No que concerne à quarta trajetória, pequenas empresas integrantes de redes comandadas por grandes empresas, as pequenas empresas fazem parte de uma cadeia de relações hierárquicas entre empresas comandadas por uma empresa-mãe. Nesse caso, a relação com as grandes empresas é de complementaridade e, em muitos casos, com fortes assimetrias e dependência. Podem ocorrer situações em que a sobrevivência e o desempenho das pequenas empresas estejam praticamente fora da esfera de suas decisões. De todo modo, fica patente que um dos inequívocos caminhos para a inserção de pequenas empresas na estrutura industrial é a complementaridade. Se associada à especialização e a um conjunto de particulares competências, a complementaridade entre grandes e pequenas empresas pode ser uma importante via para a modernização e produtividade da pequena empresa e mesmo do segmento em que ocorre tal rede de subcontratação.

Como visto, o rol das pequenas empresas é composto por empresas com características muito diferenciadas (a não ser pelo pequeno capital). Há pequenas empresas que utilizam intensamente a mão-de-obra, sem muita qualificação e de custo relativamente baixo, provavelmente apresentando alto índice de rotatividade de mão-de-obra e de empresas, tendência que pode se acentuar em um contexto no qual a competitividade esteja mais vinculada a fatores como a diferenciação do que a salários baixos. No entanto, há também pequenas empresas com capacidade de construir vantagens competitivas com base em investimentos (compatíveis com o porte) em atualização tecnológica em práticas de comercialização e em práticas de gestão.

A identificação de empresas com essas características sinaliza que pequeno porte não significa necessaria- mente estar distante da fronteira tecnológica. Aplicando modernas técnicas de gestão, essas empresas definem estratégias competitivas com foco na qualidade, na diferenciação de produtos, no relacionamento com clientes (desenvolvimento conjunto de projetos, por exemplo). A existência e a permanência desse tipo de pequenas empresas e, especialmente, a ampliação do seu número sugerem que, de fato, pode haver uma alternativa, no que tange às vantagens competitivas, em relação àquelas pequenas empresas que fundam sua competitividade na reprodução do seguinte padrão: baixa qualificação - baixos salários e benefícios sociais - baixa produtividade, e assim sucessivamente. Estruturas industriais com predominância de pequenas empresas não têm porque estar associadas a inferiores condições de trabalho. Se assim for, melhorias nesse aspecto devem constituir o objetivo básico de políticas setoriais.

O reconhecimento da acentuada heterogeneidade no segmento das pequenas empresas permite apontar a fragilidade de argumentos a favor de medidas indiscriminadas de apoio, justificadas apenas pelo porte pequeno das empresas. Quando se trata de pequenas empresas, não se justifica uma política geral, visto que elas não constituem um bloco único e homogêneo. As quatro formas destacadas têm respaldo teórico e de evidências empíricas como se mostrou ao longo do texto. Cada uma constituiu uma possível trajetória com alcance e restrições próprias, com diferentes potencialidades de contribuição para o emprego, para o desenvolvimento local, para a competitividade dos setores em que se inserem, ou mesmo como forma alternativa ao emprego. Esse é um aspecto que estatísticas sobre pequenas empresas devem levar em conta. E, mais importante, a formulação de um conjunto articulado de ações para as pequenas empresas deve considerar as especificidades e a realidade de cada uma das categorias (trajetórias) identificadas, e relacioná-las aos objetivos das ações. É nessa direção que se abrem novos caminhos para futuras pesquisas. 


\title{
Concept and space of small business in the industrial structure: heterogeneity and forms of insertion
}

\begin{abstract}
Based on the analysis of the relevant literature, this study amplifies the debate about the concept of small business and identifies the possible space for it in the industrial structure. The concept of small business has been evidenced as "small capital", whose position and performance are closely linked to the process of oligopolization. Along these lines, four possible insertion trajectories for the segment have been sought to be highlighted: struggle for space in markets still not so oligopolized and with emphasized price competition; exploration of new market niches; network organization, with predominance of small business and without the explicit leadership of big companies; and insertion into sub-contracting networks controlled by big companies. Before this group of trajectories, it is evident that it is inadequate to consider small businesses as a homogeneous block (or like a "general matter"), both in terms of the conditions that explain its survival and its growth, and the economic policy measures focused on its promotion. What matters is no longer the size, but rather the potential to contribute to the achievement of planned development results.
\end{abstract}

Keywords: Small business. Industrial structure. Insertion trajectories.

\section{Referências bibliográficas}

COPE, J. Researching Entrepreneurship Through Phenomenological Enquiry: Philosophical and Methodological Issues. International Small Business Journal, v. 23, n. 2, p. 163-189, abril, 2005.

CURRAN, J. "Specificity" and "Denaturing" the Small Business. International Small Business Journal, v. 24, n. 2, abril, p. 205-210, 2006.

CURRAN, J.; BLACKBURN, R. A. Researching the Small Enterprise. London: Sage, 2001. 192 p.

CURRAN, J.; BURROWS, R. Shifting the Focus: Problems and Approaches in Studying the Small Enterprise in the Services Sector. In: ATKIN, R.; CHELL, E.; MASON, C. (Eds.). New Directions in Small Business Research. Aldershot: Ashgate, 1993, p. 180-187.

D’AMBOISE, G.; MULDOWNEY, M. Management Theory for Small Business: Attempts and Requirements. Academy of Management Review, v. 13, n. 2, p. 226-240, abril, 1988.

DEI OTTATI, G. Local governance and industrial districts'compettitive advantage. In: BECATTINI, G. et al. From Industrial Districts to Local Development: An Itinerary of Research. Cheltenham, UK, Northampton, MA: Edward Elgar, 2003, p. 157 - 183.

DELATRE, M. Les PME face aux Grandes Entreprises. Economie et Statistique, n. 148, outubro, p. 3-19, 1982.

GIBB, A. A. SME Policy, Academic Research and the Growth of Ignorance, Mythical Conceps, Myths, Assumptions, Rituals and Confusions. International Small Business Journal, v. 18, n. 3, p. 13-35, junho, 2000.
SELltiZ, C. et al. Métodos de Pesquisa nas Relações Sociais. Tradução de Dante Moreira Leite. 3 ed. São Paulo: Editora da Universidade de São Paulo, 1974. 674 p.

SENGENBERGER, W. Economic and Social Perspectives of Small Enterprises. Labour and Society, v. 13, n. 3, p. 249-259, julho, 1988.

SFORZI, F. Local Development in the experience of Italian industrial districts. In: BECATTINI, G. et al. From Industrial Districts to Local Development: An Itinerary of Research. Cheltenham, UK, Northampton, MA: Edward Elgar, 2003, p. $157-183$.

SOUZA, M. C. A. F. Pequenas e Médias Empresas na Reestruturação Industrial. Brasília: Ed.SEBRAE, 1995. $257 \mathrm{p}$.

STEINDL, J. Small and Big Business: Economic Problem of the size of firms. Oxford: Basil Blackwell, 1945. 66 p.

Maturidade e Estagnação no Capitalismo Americano. Tradução de Leda Maria Gonçalves Maia. São Paulo: Abril Cultural, 1983. 264p.

Post-scriptum. In: STEINDL, J. Pequeno e Grande Capital. Tradução de Tamás Szmrecsányi. São Paulo: Hucitec/ Unicamp, 1990. $142 \mathrm{p}$.

TORRÈS, O.; JULIEN, P. A. Specificity and Denaturing of Small Business. International Small Business Journal, v. 23, n. 4, p. 355-377, dezembro, 2005.

YU, T. F. Toward a capabilities perspective of the small firm. International Journal of Management Reviews, v. 3, n. 3, p. 185-197, setembro, 2001. 


\section{Sobre os autores}

\section{Maria Carolina de Azevedo Ferreira de Souza}

Instituto de Economia, Universidade Estadual de Campinas - Unicamp,

Rua Rafael Sampaio, 387, CEP 13023-240, apartamento 41, bloco B, Jardim Guanabara, Campinas, SP, Brasil, e-mail: carols@eco.unicamp.br

\section{Leonel Mazzali}

Programa de Mestrado em Administração, Universidade Municipal de São Caetano do Sul, Rua João Antonio de Campos, 40, CEP 13209-280, Jardim Morumbi, Jundiaí, SP, Brasil, e-mail: leonel_mazzali@uol.com.br

Agradecimentos: Agradecemos aos revisores técnicos, pela atenção e profissionalismo. 